\title{
Corporate governance and stock liquidity in Australia: A pitch
}

\author{
Searat Ali ${ }^{\mathrm{a}, 1}$

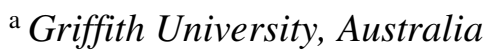

\begin{abstract}
This pitch research letter (PRL) applies the pitch template developed by Faff (2015a) to an academic project in corporate finance; that is, corporate governance and market microstructure, namely, stock liquidity for Australian firms. The pitch template is useful in identifying the core elements that form the framework of research project. This PRL encloses a brief background about the pitcher and pitch, followed by a brief commentary on the pitch and personal reflections of the pitcher on the pitch exercise itself.
\end{abstract}

Keywords: Pitching research, corporate governance, stock liquidity, Australia.

\section{JEL codes: G12, G34}

\section{Introduction}

This PRL applies the pitch template developed by Faff (2015a) to an academic project in corporate finance; that is, corporate governance and market microstructure, namely, stock liquidity for Australian firms. I commenced a $\mathrm{PhD}$ in finance at Griffith University, Australia in January 2013. My primary field of research is corporate finance. Specifically, I am investigating the association of corporate governance with various risk factors such as financial distress, stock liquidity, and downside risk. I completely agree with Faff (2015a) that the two hardest tasks about doing research are the starting and the finishing. Putting it into the perspective of my $\mathrm{PhD}$ journey, the first year was tough, but it brought plenty of experiences to my research career. The experiences are similar to what Faff (2015a) tagged "IDioTs", i.e., generating research ideas, checking the availability of relevant and reliable data, and developing the know-how about econometric

1 Corresponding author: Department of Accounting, Finance and Economics, Griffith Business School, Griffith University, 170 Kessels Road, Nathan QLD 4111, Australia; tel. (+61) (0)7 3735 7295; email address: searat.ali@griffithuni.edu.au 
tools. I did $\mathrm{PhD}$ confirmation seminar on 27 March 2014. Since then, I have completed a paper, "Does corporate governance quality reduce financial distress? New panel evidence from Australia" (see Ali, Liu and Su, 2014) and presented it at the 27th Australasian Finance and Banking Conference held in Sydney on 15-18 December 2014. I was honoured to participate, as a $\mathrm{PhD}$ travel grant recipient, in the 75th annual meeting of the American Finance Association (AFA) held in Boston on 2-5 January 2015.

Taking other tasks and deadlines into consideration, I started the pitch exercise from 8 January 2015 and completed it on 18 January 2015. This pitch exercise included background reading on pitching research (Faff, 2015b) and discussion with my supervisors. Similar to Beaumont (2015), I used a "non-linear" approach to complete the pitch. I started completing the sections that were foremost in my mind and skipped the sections that required deeper contemplation. After this initial pass, I worked randomly to complete each section. Once I had each section roughly outlined, I went back and worked on refining each section, paying special attention to the advice given by Faff (2015a) in "cues for the pitcher".

The remainder of this PRL is organised as follows. Section 2 gives a brief commentary on the completed pitch, Section 3 covers personal reflections on the pitch exercise, and the final section provides the conclusion.

\section{Brief commentary on the pitch}

Table 1 presents the pitch on the topic of corporate governance and stock liquidity in Australia (item A), which was completed on 18 January 2015. The primary research question (item $B$ ) is "do better governed firms have greater stock liquidity in Australia?" The key research papers (item $C$ ) that relate to the stated research question are Chung et al. (2010), Chai et al. (2010), and Beekes et al. (2015). Of these papers, the most critical and directly linked paper to the proposed research idea is Chung et al. (2010), who investigate the association between corporate governance and stock liquidity in the US. The other two papers are also important because they are related to the Australian context. Specifically, the Chai et al. (2010) paper guides me on the determinants of stock liquidity in Australia. While the paper does not incorporate corporate governance quality (CGQ), it provides an insight on the stock liquidity proxies. Since I argue that CGQ affects stock liquidity through the channel of information disclosure, it is vital to prove that the relation between CGQ and disclosure exists. The paper of Beekes et al. (2015) is important in this regard; Using the Horwath ratings as a measure of CGQ (in this proposed research I am using the same ratings), they find a significant positive relation between CGQ and informativeness of disclosure in Australia. The proposed research is mainly motivated (item $D$ ) by a lack of empirical research on the corporate governance as a critical determinant of stock liquidity in Australia, and the institutional differences that Australia has compared to the US. 
Table 1. Completed 2-page pitch template on corporate governance and stock liquidity

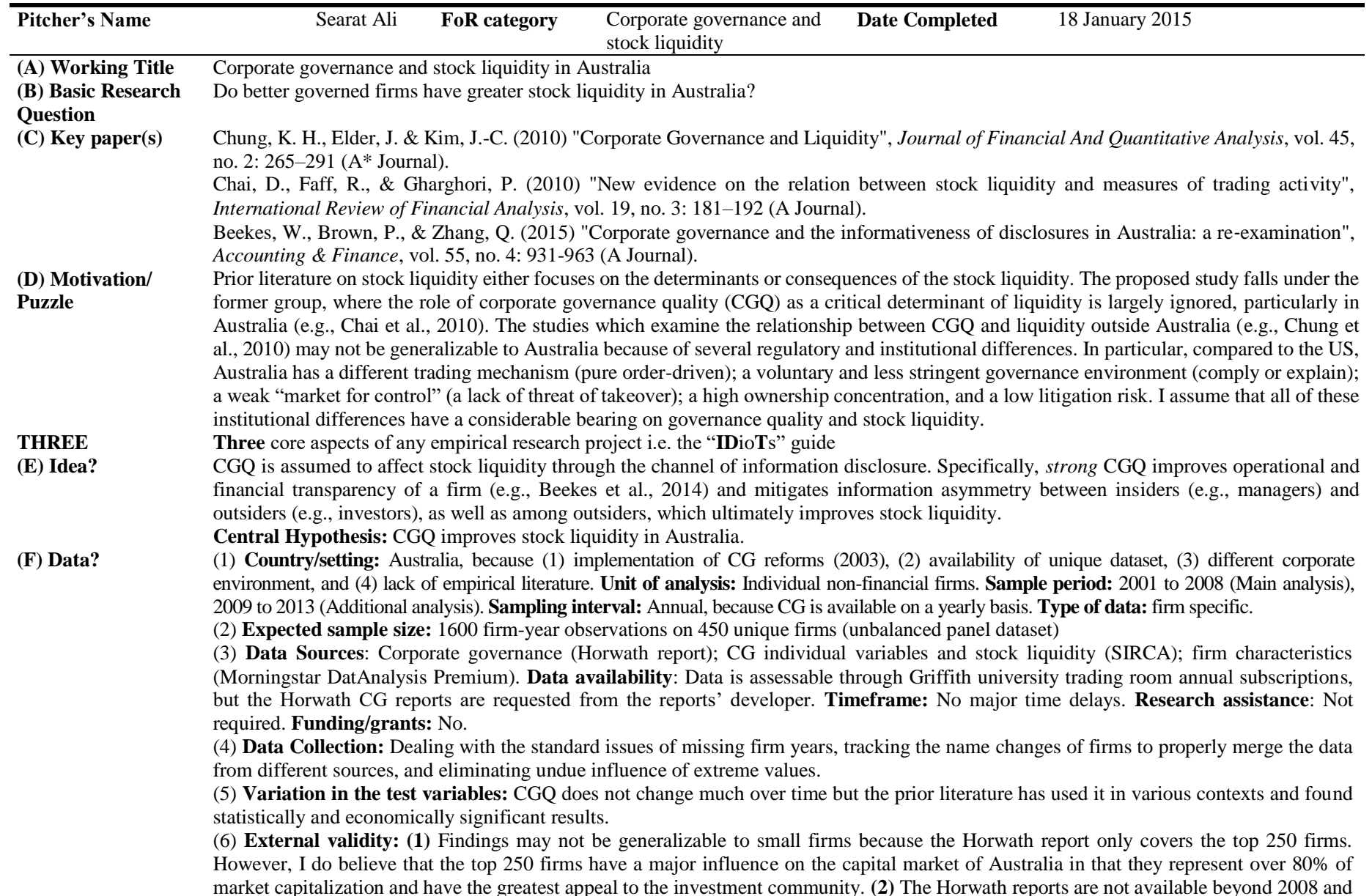



2013 for small, medium, and large firms, and to check if the results are robust. Construct validity: Yes, because the Horwath report pays special attention to the aspects that have been viewed as important in CG best practice codes in Australia and elsewhere. I plan to use stock liquidity proxies from three dimensions (trading cost, price impact, and immediacy) that are calculated by using quote-, price-, and volume-based data.

(G) Tools? $\quad$ Empirical framework: (1) Pooled OLS regression approach, where standard errors are clustered by firm to control for heteroskedasticity and within-firm correlation in residuals. (2) Alternative panel data estimation methods such as GLS random effect or fixed effect regressions and Between Estimators. (3) To pecluch GMM to control all sources of endogeneity. (5) Robustness checks deal with survivorship bias and sensitivity of results to global financial crisis and ownership concentration. Econometric software: STATA 13. Econometric Skills: Own + supervisors.

TWO Two key questions

(H) What's New? Novelty: The relationship between CGQ and stock liquidity has not been tested in Australia, so the novelty is in the data. To capture CGQ, I am using the unique dataset of the Horwath report plus I am developing a similar index beyond 2008 for different size firms. The prior studies using the Horwath report are either cross-sectional or they link CG to organizational activities other than stock liquidity, such as firm performance, information disclosure, and corporate social responsibility. This study provides additional evidence on the usefulness of the Horwath report in determining stock liquidity. Data is the driver whereas idea and tools are the passengers. Mickey Mouse/ Venn diagram. Yes

(I) So What? Given CGQ is instrumental to stock liquidity in Australia, investors, firms, and regulators may wish to monitor the CG mechanisms more closely so as to devise sound trading strategies, corporate environment, and trading regulations respectively. (1) Stock liquidity provides an ease of converting cash into stock and vice versa. Knowing that CG improves stock liquidity, investors can select stocks and construct portfolios with better CGQ. (2) Stock liquidity can lower transaction costs and increase the demand of a firm's stock; hence reducing cost of capital of a firm. Knowing that CG improves stock liquidity, firms can focus on CGQ and accrue the benefits (3) If CG improves stock liquidity, this gives empirical support to the regulators to design appropriate trading regulations.

ONE

(J) Contribution?

One bottom line

Considerations

\section{Collaboration:}

It is desired.

Idea: Not required

Data: CGQ affects liquidity through the channel of information disclosure. External collaboration may be required to obtain disclosure data. Tools: Yes, internal collaboration.

Target Journal(s): Journal of Banking and Finance; or Accounting and Finance; or Applied Economics.

"Risk" assessment:

-"no result" risk: Very low.

-"competitor" risk: Medium, because the Horwath reports are not publicly available. Even if available, it requires sufficient time to organize data in a testable format.

- "obsolescence" risk: Low; CG has received wide attention from researchers and regulators in the recent decade, and it is expected to remain as a "hot topic".

Other Challenge: The main challenge I have in executing this plan, is why Australia as a case study? 
The remainder of Table 1 outlines "answers" to all the required fields from the Faff (2015a) template; namely, Idea, Data, Tools, What's New, So What, Contribution, and other Considerations. The material included relating to all of these is selfexplanatory from the pitch template itself, and thus I feel that no further comment is needed here.

\section{Personal reflection on the pitch exercise}

\subsection{First hearing}

How did I come to know about the pitching exercise? The first time, I heard about "pitching a research" was from a fellow PhD student who was participating in the AFAANZ PhD symposium in 2014. At that time, I was analysing the data and interpreting the results of my first research paper on corporate governance and financial distress. As I remember, I asked my colleague, "Can I use this pitch template?" He told me "Yes you can, but you need to seek permission from Professor Faff, and you have to send him the completed pitch for his feedback". It takes only a few minutes to send an email and seek permission, but I could not do so for couple of reasons. First, I work best when there is a certain deadline approaching - this might not be a good habit, but it works well for me. Since there was no deadline, I was unable to motivate myself. Second, I thought, "I am halfway through to my paper, and the pitch exercise might not be useful at this stage", though I was not right in my habit and belief, as I realised after completing this PRL since creating one's own deadlines and using the pitch template at any stage of research is helpful to uplift the level of motivation and focus in research.

\subsection{Second hearing}

How did I come to know about the pitching exercise? The second time, I heard about "pitching a research" was from SIRCA when they sent an email with the subject Call for Papers - SIRCA YRW 2015 'Pitching Research' Symposium on 20 November 2014. ${ }^{2}$ At this time, I was reviewing literature for a second paper on stock liquidity. I thought that this was the perfect time to use the pitch template. On top of this, the deadline (19 January 2015) to submit PRL was there. I discussed it with my supervisors, who strongly encouraged me to participate in the symposium.

\subsection{Biggest challenge}

What's new/Contribution? The biggest challenge to any research is its contributions, and this applied to my research, too. While I was doing the pitch

${ }^{2}$ http://www.sirca.org.au/2014/11/sirca-pitching-research-symposium-call-for-papers/ 
exercise, I asked myself if the CGQ and liquidity relation had been tested outside Australia (e.g., Chung et al., 2010); why there is a need to test such a relation in Australia? I found the recommendation of Faff (2015a) useful in this regard. He recommends that "the researcher needs to make a compelling case as to why it is "dangerous' to extrapolate the distilled evidence from X, Y and Z to country A". Following his advice, I read more literature and then identified several regulatory and institutional differences (e.g., such as order-driven trading mechanism, voluntary CG environment and high ownership concentration) that cast a doubt on the generalizability of results from the US to Australia (item D). In addition to this, recent corporate governance reforms (2003) in Australia, and the availability of unique corporate governance dataset in the form of the Horwath ratings make Australia an interesting setting (item $F$ ) in which to investigate the linkage between CGQ and stock liquidity. Moreover, I spent substantial time in reviewing the literature that applied ideas from US-based papers to the non-US-based settings and were published in the top tier journals. The common theme I learnt is that these papers pay special attention to the institutional and regulatory differences. I realize that I have to spend more time on this aspect of my research to make it a success story.

\subsection{Venn diagram and my teaching strategy}

How do Mickey Mouse and the Venn diagram match my aptitude? I believe "a picture is worth a thousand words", and this is why, graphs and flow charts are the integral parts of my teaching strategy. I believe that transcribing the complex passages and concepts into flow charts makes it easy for the readers to understand. I use this strategy up to an extent that my students gave me the title of Mr Flow Chart. The success of this strategy in classroom is reflected in my Student Experience of Teaching (SET) as follows:

"Lesson sheets, linking lecture concepts to the tutorials and equations... was amazing!!!! He has an amazing way to explain and present information that any student can grasp easily." (7211AFE, 2015)

"Good ability to explain complex problem by using simple examples" (7211AFE, 2014)

"He always made sure everyone understood the content before moving on, he was really good at explaining the content and helping students, provided us with clear instructions about all assessments and course material, one of the best lecturers I have had so far" (2206AFE, 2015)

Given my positive classroom experience on flow charts, I found the Venn diagram, as proposed by Faff (2015a), as a simple but effective way to position my research in the context of existing literature. Figure 1 shows the Venn diagram applied to my research idea. 


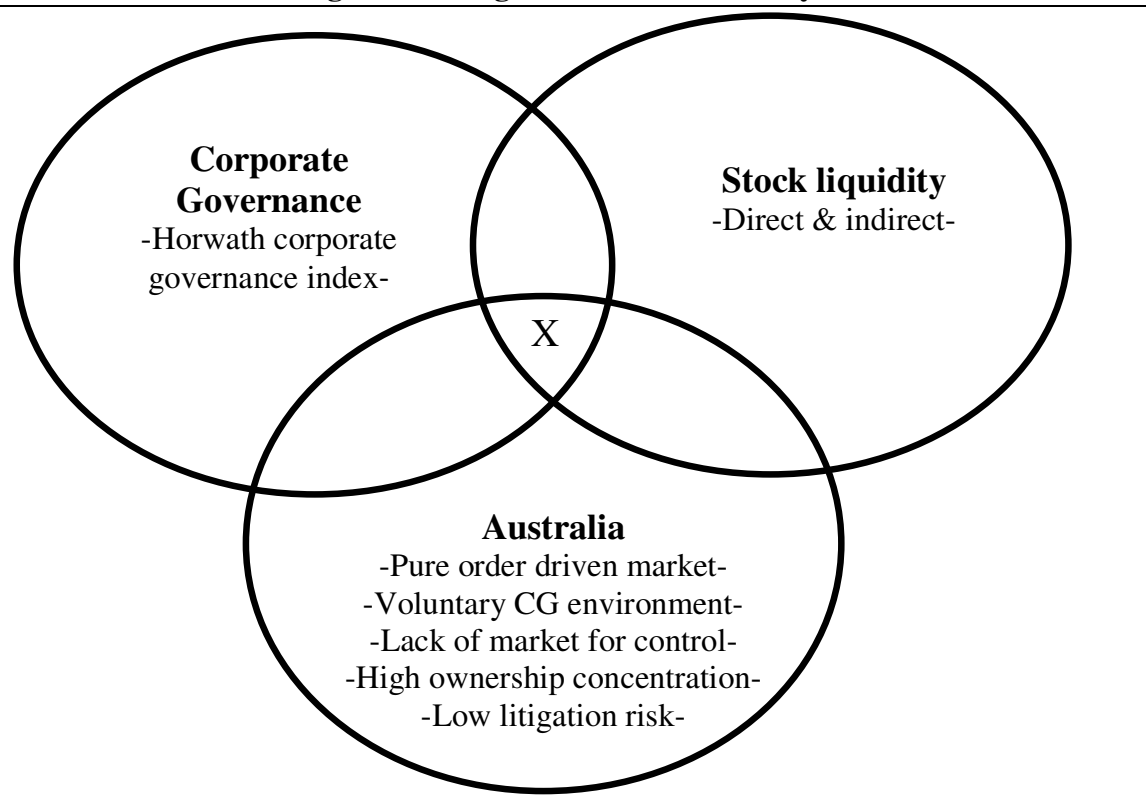

Figure 1. Mickey Mouse diagram characterizing novelty of my research idea

\subsection{Some insights}

What I have learnt from the pitch exercise? After completing this PRL, I realised that the Faff (2015a) pitch template is useful not only for new ideas but also for working papers. I also believe that Faff's template can be used to evaluate the key papers in terms of 3-2-1 "countdown". Further, I realised that there are high chances of making mistakes. I may claim contributions that do not make sense and may fail to pick the contributions that do make sense. To mitigate these concerns, I feel it is important to discuss the research idea in the early phase with as many scholars as possible including advisors and senior faculty, both internal and external. The problem that might arise is that an experienced researcher with a tight schedule might not be able to read a research proposal of 10 to 15 pages long. In such scenario, I believe a two-page pitch template is quite helpful.

\section{Conclusion}

Based on the Faff (2015a) guidelines, this PRL covers the basic pitch for a proposed research project on corporate governance and stock liquidity in Australia. This PRL was initially developed for SIRCA's pitching research symposium. The purpose of preparing the PRL and participating in the symposium was to receive 
constructive feedback from experienced researchers that would ultimately enable me to refine the research idea. One of the best aspects of the pitch exercise was that it forced me to think over and over on each section, and enabled me to synthesize scattered ideas in a systematic way. Given the benefits of the pitch exercise, I will use the pitch template throughout my research career, and I strongly encourage other researchers to use Faff's pitch template to develop and map their research ideas.

\section{Acknowledgement}

This PRL is prepared for the second empirical chapter of the author's doctoral thesis at Griffith University. The author thanks his supervisors Benjamin Liu and Jen Je Su, and Robert Faff, David Michayluk, Petko Kalev, Sue Wright, Gary Monroe, Steve Easton, and the participants at the Securities Industry Research Centre of Asia-Pacific (SIRCA) pitching research symposium for their helpful comments and discussions to effectively execute the proposed research project. The author is also grateful to Griffith University Postgraduate Students Association (GUPSA) for the English editing. The author is responsible for any remaining error.

\section{References}

Ali, S., Liu, B. \& Su, J. J. (2014) "Does corporate governance quality reduce financial distress? New panel evidence from Australia", Available at SSRN: http://papers.ssrn.com/sol3/papers.cfm?abstract_id=2481892.

Beaumont, S. J. (2015) "An investigation of the short- and long-run relations between executive cash bonus payments and firm financial performance: A pitch", Accounting \& Finance, vol. 55, no. 2: 337-343

Beekes, W., Brown, P. \& Zhang, Q. (2015) "Corporate governance and the in formativeness of disclosures in Australia: a re-examination", Accounting \& Finance, vol. 55, no. 4: 931-963

Chai, D., Faff, R. \& Gharghori, P. (2010) "New evidence on the relation between stock liquidity and measures of trading activity", International Review of Financial Analysis, vol. 19, no. 3: 181-192

Chung, K. H., Elder, J., \& Kim, J.-C. (2010) "Corporate Governance and Liquidity", Journal of Financial and Quantitative Analysis, vol. 45, no. 2: 265-291

Faff, R. W. (2015a) "A simple template for pitching research", Accounting \& Finance, vol. 55, no. 2: 311-336

Faff, R. W. (2015b) "Pitching research", Available at SSRN: http://ssrn.com/abstract=2462059 or http://dx.doi.org/10.2139/ssrn.2462059 